\title{
Comparison between the Effect of Local Katira Gum and Xanthan Gum on the Rheological Properties of Water-based Drilling Fluids
}

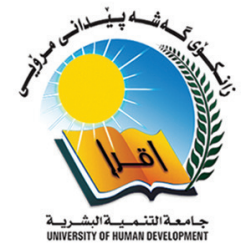

\author{
Bayan Qadir Sofy Hussein ${ }^{1 *}$, Khalid Mahmood Ismael Sharbazheri', \\ Nabil Adiel Tayeb Ubaid ${ }^{2}$
}

${ }^{1}$ Department of Engineering, Kurdistan Institution for Strategic Study and Scientific Research, Sulaimani Polytechnic University, Sulaimani, Iraq, ${ }^{2}$ Department of Petroleum and Energy Engineering, Faculty of Engineering, Sulaimani

Polytechnic University, Sulaimani, Iraq

\section{A B S T R A C T}

The rheological properties of drilling fluids have an important role in providing a stable wellbore and eliminating the borehole problems. Several materials including polymers (xanthan gum) can be used to improve these properties. In this study, the effect of the local Katira, as a new polymer, on the rheological properties of the drilling fluids prepared as the bentonite-water-based mud has been investigated in comparison with the conventional xanthan gum. Experimental work was done to study of rheological properties of several gums such as, local katira gum, and xanthan gum bentonite drilling mud. Different samples of drilling fluids are prepared adding the xanthan gum and local katira to the base drilling fluid at different concentrations using Hamilton Beach mixer. The prepared samples are passed through rheological property tests including the apparent viscosity, plastic viscosity, and yield point (YP) under different temperature conditions. The obtained results show that the viscosity is increased from 5 to $8.5 \mathrm{cp}$ and YP is increased from 18.5 to $30.5 \mathrm{lb} / 100 \mathrm{ft}^{2}$, with increasing the concentration of the xanthan gum from 0.1 to 0.4 . However, the effect of the local katira in increasing the viscosity and YP is lower compared with the xanthan gum, which are ranged between 5-6 cp and 18.5-20.5 cp.

Index Terms: Drilling mud, Polymer, Rheological properties, Xanthan gum, and Katira gum

\section{INTRODUCTION}

Drilling fluid which is simply called mud is one of the most important systems of drilling the borehole to extract hydrocarbon [1], [2]. This kind of fluid is used for providing several functions including bottom hole cleaning, providing a balance between borehole pressures, and controlling the wellbore stability [3]. To achieve these applications, the

\begin{tabular}{|l|l|}
\hline Access this article online \\
\hline DOI: 10.21928/undjst.v4n2y2020.pp18-27 & $\begin{array}{l}\text { E-ISSN: 2521-4217 } \\
\text { P-ISSN: 2521-4209 }\end{array}$ \\
\hline
\end{tabular}

Copyright (C) 2020 Hussein, et al. This is an open access article distributed under the Creative Commons Attribution Non-Commercial No Derivatives License 4.0 (CC BY-NC-ND 4.0) drilling fluids must be prepared with practicable properties that have a significant role, such as rheological and filtration properties [4]. For this purpose, many chemical additives are used including clays, solvents, and polymers. Polymers in different types are widely used with the water-based muds to improve the rheological properties of the mud, and the mud is sometime called polymer mud [5]-[7]. At present, researchers and companies are more focusing on the application of biopolymers which are definitely not poisonous and cheaper while having significantly less influence on formation damage [8], [9].

Natural gum polymers are widely used in the industry and studied by many researchers at the modern drilling process due to its low cost and high performance. Gums are

\section{Corresponding author's e-mail: Bayan Qadir Sofy Hussein, Department of Engineering, Kurdistan Institution for Strategic Study and Scientific} Research, Sulaimani Polytechnic University, Sulaimani, Iraq. E-mail: bayan.sofy@kissr.edu.krd 
generally used to provide a good influence on the rheological characteristics of several water-based drilling fluids that prepared from the mixture of water and bentonite [10], [11]. Several types of gum polymers that are used in drilling fluid application are suggested in the literature by researchers, such as tragacanth gum [8], xanthan gum [12], [13], tamarind tree gum [14], carboxymethyl cellulose [15], [16], and modified natural gum including diutan gum [17]. Among the gum polymers, guar and xanthan gums are most commonly used to modify the rheological and filtration properties of the waterbased drilling fluids [11]. However, the identification and investigation of new types of the natural gums are necessary.

In 2018, Weikey et al. [9] investigated the effect of different gums including Babul, Dhawda, Katira, and Semal gums of the performance of the water-based mud. Their results showed that Babul, Semal, and Katira improved the rheological properties of the mud, however, Dhawda gum showed the highest performance. The comparison between the influences of the tamarind gum and polyanionic cellulose on the bentonite-water suspensions is investigated experimentally by Mahto and Sharma [14]; consequently, the tamarind gum produced more favorable rheological properties, optimal fluid loss, and lower formation damage at very low concentrations compared with the polyanionic cellulose. In addition, Benyounes et al. [15] investigated the effect of carboxymethyl cellulose and xanthan gum on rheological properties of the water-based mud. Their laboratory results revealed that the viscosity and yield point (YP) of bentonite suspension are increased and the flow index is decreased with increasing the xanthan concentration. However, carboxymethyl cellulose caused to increase viscosity along with decreasing the YP. On the other hand, Benmounah et al. [16] confirmed that the presence of carboxymethyl cellulose in the bentonite suspension helps to remove the yield stress and increase the viscosity of the mixture, and the xanthan gum induces an increase in the yield stress and in viscosity of the drilling muds. Dewangan and Sinha [18] developed water-bentonite suspension from the Babul tree gum and carboxymethyl cellulose and studied using marsh funnel. The results revealed that better rheological properties of mud can be achieved with using carboxymethyl cellulose compared with the Babul tree gum. However, they claimed that the Babul gum can be used to improve the rheological properties of mud to a favorite level. More recently in 2019, Ali et al. [19] enabled to greatly improve the rheological and filtration properties of the water-based mud by combining the xanthan gum with a nanocomposite of $\mathrm{SiO}_{2} / \mathrm{ZnO}$. In their work, the viscosity and gel strength are increased from $9 \mathrm{cP}$ and $20 \mathrm{lb} / 100 \mathrm{ft}^{2}$ to $22 \mathrm{cP}$ and $49 \mathrm{lb} / 100 \mathrm{ft}^{2}$, respectively.
While, the fluid loss and filter cake are reduced by $54 \%$ and $92.5 \%$, respectively.

The ultimate goal of this work is to investigate the effect of two polymers (xanthan and natural Katira gum) on the rheological behaviors of bentonite-water-based drilling fluid. For this purpose, different samples of drilling fluids are prepared at different concentrations of polymer gums. The rheological viscometer is used to study the viscosity and YP of the prepared drilling fluids under the effect of types of gum, concentration of gum, and test temperature.

\section{MATERIALS AND METHODOLOGY}

\subsection{Materials}

The drilling mud mixture utilized in this research are freshwater, bentonite, natural katira gum, and xanthan gum. The freshwater is used as the base fluid and for fluid conditioning, the bentonite along with other additives utilized in the drilling fluid formulations. The purpose of adding biopolymers, natural katira gum, and xanthan gum is used to increase viscosity and fluid loss control. The bentonite which is composed mostly of montmorillonite obtained from one of the Kurdistan's drilling companies. The additives utilized are natural katira gum that is purchased from the local market and xanthan gum is supplied from petroleum engineering department of Sulaimani Polytechnic University.

\subsection{Xanthan Gum}

Xanthan gum is the polysaccharide anionic item within a commercial level gained from the aerobic agitation of Xanthomonas campestris bacteria. Xanthan gum has a strong stability to the different conditions of heat, salinity, and $\mathrm{pH}$ [20]. One of the most attractive characteristics of xanthan is its ability to increase the viscosity for the drilling fluid with very low concentration [21]. Xanthan gum has a simple chemical structure as shown in Fig. 1 that comes with a typical molecular weight of $3 \times 10^{5}-7.5 \times 10^{6} \mathrm{~g} /$ mole [22]

\subsection{Local Katira Gum}

Katira gum is mainly exist in rocky locations of Kurdistan Mountain. High-quality gum was harvested and dried during the spring season from April to June. It has mostly acetylated complex polysaccharide and includes about $80 \%$ acetyl groups as well as about $37 \%$ uronic acid remains with acidic quantity varying from 17.4 to 22.7 . According to Weikey et al. [9], the molecular weight of Katira is about $9.5 \times 10^{6} \mathrm{~g} / \mathrm{mol}$. At low concentrations, Katira are capable to create a high gluey gum with a good swelling behavior due to the existence of the acetyl groups [9]. 
Katira gum is the sap of the thorny plant which mainly presents in Middle Eastern and West Asian countries. This particular gum is odor free, flavorless, and water-soluble mixing extracted from their drain for the plant. The gum through the plant will be gained obviously through the root and through cuts produced in their stem then dehydrated to be able to creates small pieces (Fig. 2).

\subsection{Preparation of Drilling Fluids}

The drilling fluids are prepared using 3-speed Type HMD200 Hamilton Beach mixer. The base drilling fluid is prepared from mixing $22.5 \mathrm{~g}$ bentonite within $350 \mathrm{~mL}$ distilled water within the mixing cup. Afterward, to identify the effect of the xanthan and Katira polymer gums on the rheological properties of the drilling mud, both polymers are separately added into the prepared base drilling fluids at different concentrations. For preparing the xanthanbased drilling mud, four samples of muds are prepared at different concentrations of $0.1,0.2,0.3$, and $0.4 \mathrm{~g}$, and four
Katira drilling fluids are prepared at 20, 40, 60, and $80 \mathrm{mg}$ concentrations (Table 1).

\subsection{Rheological Measurements}

For the prepared drilling fluids shown in Table 1, the six-speed rotary viscometer model ZNN-D6 is used to measure the rheological properties including apparent viscosity, YP, plastic viscosity (PV), and $\mathrm{YP} / \mathrm{PV}$ proportion dependent on the shear

\section{TABLE 1: Formulation of the prepared drilling fluids}

\begin{tabular}{llcc}
\hline Mud sample & Polymer gum & Concentration & Additives, g \\
\hline S0 & ---- & --- & Bentonite, 22.5 \\
XS1 & Xanthan & $0.1 \mathrm{~g}$ & \\
XS2 & & $0.2 \mathrm{~g}$ & \\
XS3 & & $0.3 \mathrm{~g}$ & \\
XS4 & & $0.4 \mathrm{~g}$ & \\
KS1 & Katira & $20 \mathrm{mg}$ & \\
KS2 & & $40 \mathrm{mg}$ & \\
KS3 & & $60 \mathrm{mg}$ & \\
KS4 & & $80 \mathrm{mg}$ & \\
\hline
\end{tabular}

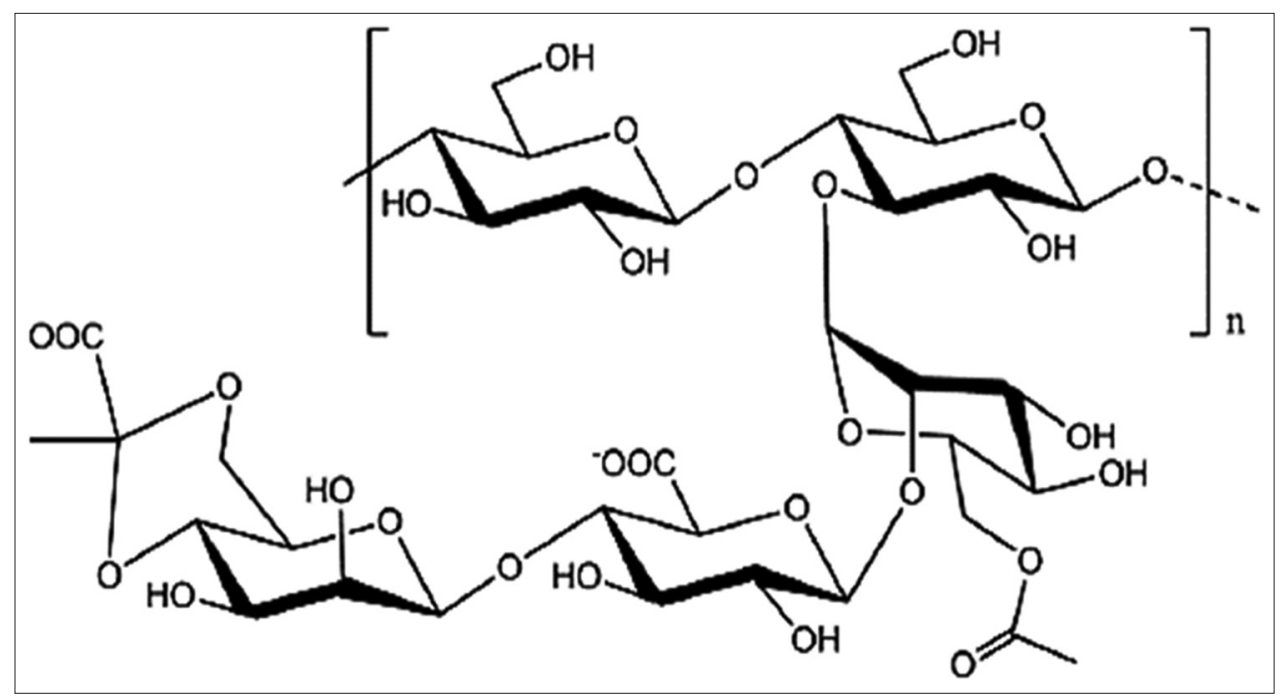

Fig. 1. Xanthan gum chemical structure [13].

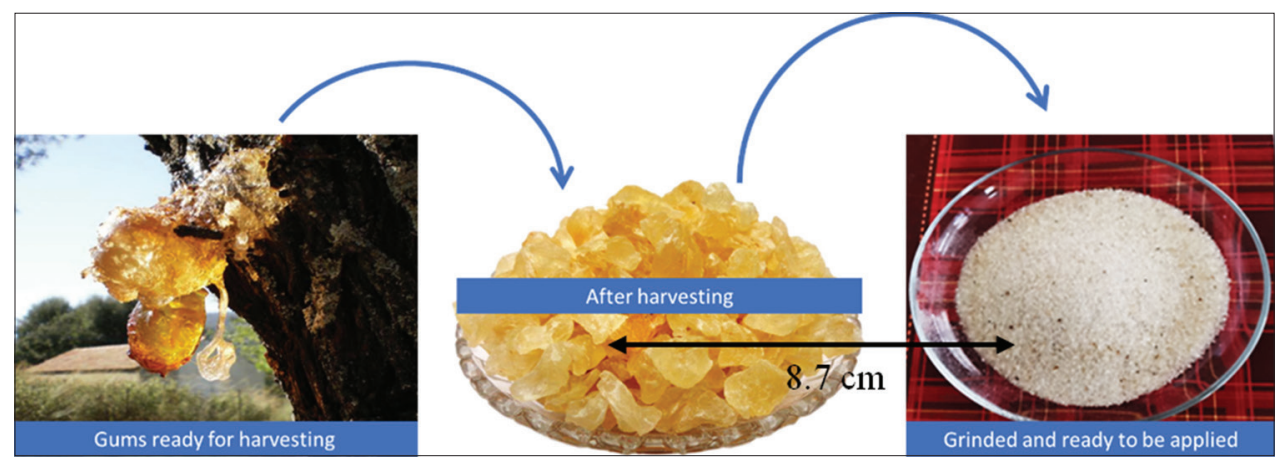

Fig. 2. The natural Katira gum on the tree, after harvesting and as a powder. 
stress and shear rate. These measurements are performed at different temperature conditions of 25,45 , and $75^{\circ} \mathrm{C}$. In general, the following procedural steps in accordance with [23] application programming interface specification $13 \mathrm{~A}$ are applied:

- The mud mixture prepared using $22.5 \pm 0.01 \mathrm{~g}$ of bentonite added into $350 \mathrm{~cm}^{3}$ of fresh water while stirring in the mixer putting the gums added at various concentrations.

- Immediately after mixing $5 \pm 0.5 \mathrm{~min}$, the container taken from mixer and cleaned using spatula to remove bentonite on container walls, making sure bentonite adhering into the spatula is actually included in the mixture.

- Replacing the container in the blender following an additional $5 \mathrm{~min}$ as the edges scraped to free any clay adhering to container and blending again for $10 \mathrm{~min}$, complete mixing duration will equate to $20 \pm 1 \mathrm{~min}$.

- Put the mixture into viscometer cup supplied with the direct-indicating viscometer. The dial readings at 600 $\mathrm{r} / \mathrm{min}$ as well as $300 \mathrm{r} / \mathrm{min}$ rotor speed settings of the viscometer will be recorded whenever a constant value for every $\mathrm{r} / \mathrm{min}$ is achieved. The test temperature was $25 \pm 1{ }^{\circ} \mathrm{C}$.

- The PV, YP, and YP/PV ratio are generally calculated using the following equations:

$$
\begin{gathered}
\mathrm{Pv}_{\mathrm{v}}=\mathrm{R} 600-\mathrm{R} 300 \\
\mathrm{YP}=\mathrm{R} 300-\mathrm{PV} \\
\mathrm{C}=\frac{\mathrm{YP}}{\mathrm{PV}} \\
\mathrm{AV}=\frac{\mathrm{R} 600}{2}
\end{gathered}
$$

where:

PV: Plastic viscosity in cp, centipoises.

YP: Yield point in $\mathrm{Ib} / 100 \mathrm{ft}^{2}$.

C: YP/PV ratio.

R600: The viscometer dial reading at $600 \mathrm{rpm} / \mathrm{min}$.

R300: The viscometer dial reading at $300 \mathrm{rpm} / \mathrm{min}$.

\section{RESULTS AND DISCUSSION}

\subsection{Effect of Xanthan Gum on Rheological Properties}

By adding different concentrations of xanthan gum into the base drilling fluid, four samples (XS1, XS2, XS3, and XS4) are prepared. Fig. 3 shows the values of the reordered viscometer readings at different speeds starting from the low shear stresses 3 and 6 rpms to moderate 100 and $200 \mathrm{rpms}$ and high shear stresses of 300 and $600 \mathrm{rpms}$. With increase the shear stress and the rotation speed per minute, the recorded value of shear rate is increasing. The same effect can be seen with increasing the concentration of the xanthan gum. The measured results of the rheological properties including the apparent viscosity, PV, YP, and PV to YP ratio under the influence of the xanthan gum are shown in Table 2. The measurements are carried out under different temperature conditions of 25,45 , and $75^{\circ} \mathrm{C}$.

Fig. 4 illustrates the values of the apparent viscosity measured for the prepared drilling fluids containing the xanthan gum at different concentrations of $0.1,0.2,0.3$, and $0.4 \mathrm{~g}$. As can be seen, the apparent viscosity of the base mud is increased from 14.25 to $21.25 \mathrm{cP}$ with adding $0.1 \mathrm{~g}$ of the xanthan gum and continued to increase to $28.25 \mathrm{cP}$ with increasing the concentration of xanthan to $0.4 \mathrm{~g}$. While, the apparent viscosity with all concentrations of xanthan gum is decreased with increasing the temperature of the experiment from 25 to 45 and $75^{\circ} \mathrm{C}$. In general, the apparent viscosity of XS1, $\mathrm{XS} 2$, and XS3 samples is reduced by about $9 \%$ with increasing temperature from 25 to $75^{\circ} \mathrm{C}$.

The PV behavior of the mud samples developed from different concentrations of xanthan gum is shown in Fig. 5. As can be seen, the PV of the base fluid is increased by $40 \%$ from 5 to $8.5 \mathrm{cP}$ by adding $0.4 \mathrm{~g}$ of xanthan gum under $25^{\circ} \mathrm{C}$. However, the impact of the xanthan in improving the PV is lower when the temperature of the experiment is increased. This is true with Benyounes et al. [15], where they demonstrate that the rheological behavior of the polymer solution predominates compared to their clay suspension system. In this situation, the macroscopic behavior for the bentonite-xanthan mixtures is influenced by xanthan.

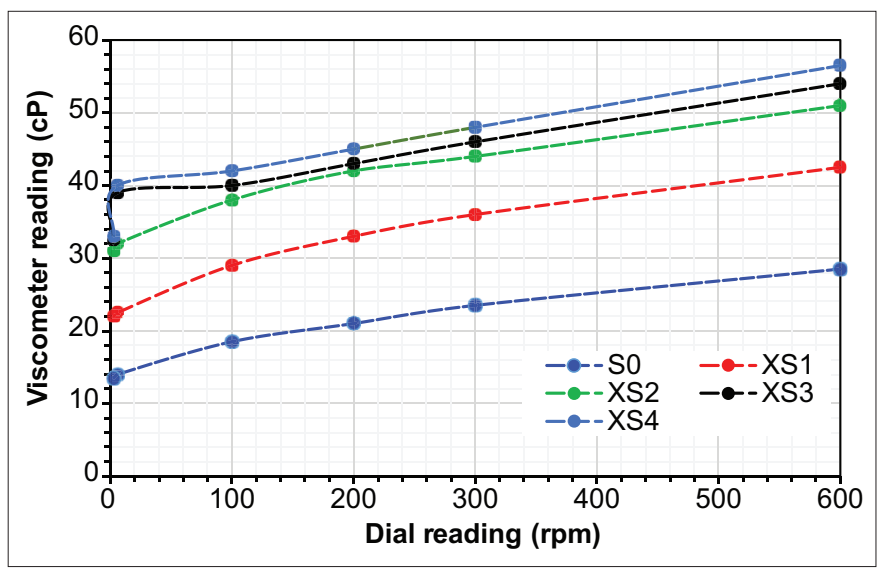

Fig. 3. Shear rate versus shear stress at various concentrations of xanthan gum and room temperature. 
TABLE 2: Measured rheological properties of drilling fluids under the influences of xanthan gum at 25, 45 , and $75^{\circ} \mathrm{C}$

\begin{tabular}{|c|c|c|c|c|c|c|c|c|c|c|c|c|}
\hline \multirow[t]{2}{*}{ Mud sample } & \multicolumn{3}{|c|}{$\mathrm{AV}(\mathrm{cP})$} & \multicolumn{3}{|c|}{$P V(c P)$} & \multicolumn{3}{|c|}{ YP (Ib/100 ft') } & \multicolumn{3}{|c|}{ YP/PV } \\
\hline & $25^{\circ} \mathrm{C}$ & $45^{\circ} \mathrm{C}$ & $75^{\circ} \mathrm{C}$ & $25^{\circ} \mathrm{C}$ & $45^{\circ} \mathrm{C}$ & $75^{\circ} \mathrm{C}$ & $25^{\circ} \mathrm{C}$ & $45^{\circ} \mathrm{C}$ & $75^{\circ} \mathrm{C}$ & $25^{\circ} \mathrm{C}$ & $45^{\circ} \mathrm{C}$ & $75^{\circ} \mathrm{C}$ \\
\hline So & 14.2 & 14.2 & 14.2 & 5.0 & 5.0 & 5.0 & 18.5 & 18.5 & 18.5 & 3.7 & 3.7 & 3.7 \\
\hline Xs1 & 21.2 & 20.5 & 18.5 & 6.5 & 5.0 & 4.0 & 29.5 & 31.0 & 29.0 & 4.5 & 6.2 & 7.3 \\
\hline XS2 & 25.5 & 24.5 & 23.0 & 7.0 & 5.5 & 5.0 & 37.0 & 38.0 & 36.0 & 5.3 & 6.9 & 7.2 \\
\hline XS3 & 27.0 & 26.0 & 24.5 & 8.0 & 6.5 & 6.0 & 38.0 & 39.0 & 37.0 & 4.8 & 6.0 & 6.2 \\
\hline XS4 & 28.2 & 26.5 & 25.7 & 8.5 & 7.0 & 6.5 & 39.5 & 39.0 & 38.5 & 4.6 & 5.6 & 5.9 \\
\hline
\end{tabular}

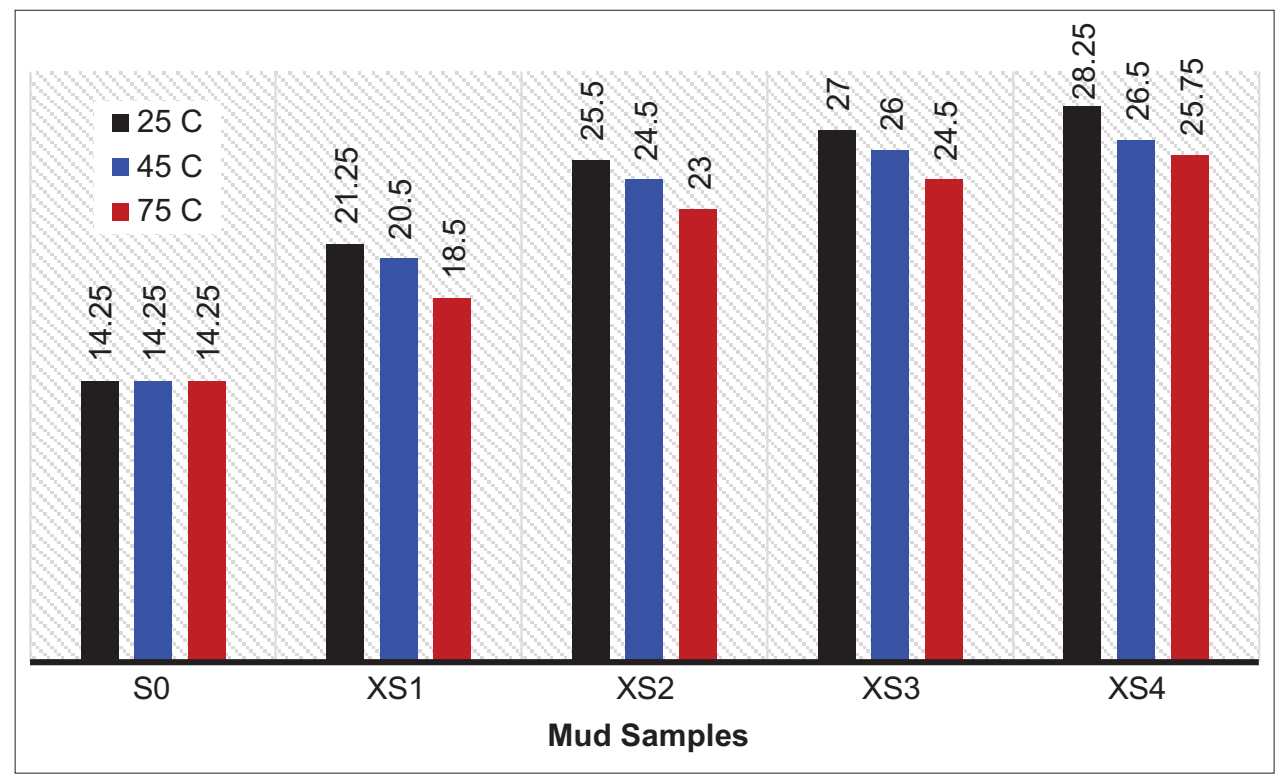

Fig. 4. Apparent viscosity measured at different concentrations of xanthan gum at 25,45 , and $75^{\circ} \mathrm{C}$.

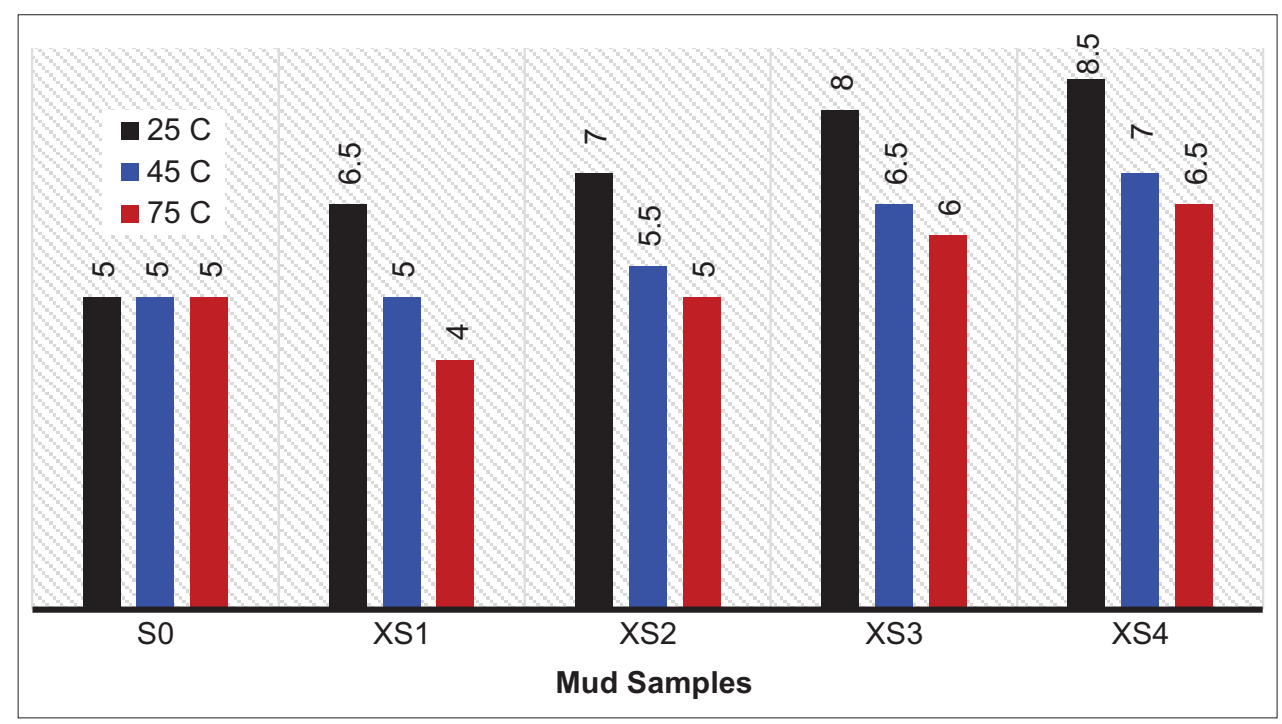

Fig. 5. Plastic viscosity measured at different concentrations of xanthan gum at 25,45 , and $75^{\circ} \mathrm{C}$. 
In addition, the values of the measured YPs for four prepared mud samples of xanthan gum are shown in Fig. 6. The used xanthan gum left the highest impact on the YP compared with other properties of the drilling fluids which is about $53 \%$. The value of the YP is increased from 18.5 to 29.5 $\mathrm{lb} / 100 \mathrm{ft}^{2}$ with adding $0.1 \mathrm{~g}$ xanthan, continued to increase to $39.5 \mathrm{lb} / 100 \mathrm{ft}^{2}$. Furthermore, the ratio of the YP to PV calculated from the measured properties of the drilling fluid samples under the influence of the xanthan gum and different temperature is shown in Fig. 7. As is obvious, the ratio between two considered parameters is varied dependents on the concentration of the xanthan gum and temperature. The high ratios between two parameters with XS1 and XS2 samples are obtained, especially at high temperatures.

\subsection{Effect of Natural Katira Gum on Rheological Properties}

To identify the impact of the Katira gum on the rheological properties of the drilling mud, the prepared Katira in powder is added into the base drilling mud at different concentrations. For the concentrations of $20 \mathrm{mg}, 40 \mathrm{mg}, 60 \mathrm{mg}$, and $80 \mathrm{mg}$, four samples of Katira gum (KS1, KS2, KS3, and KS4) are prepared.

Fig. 8 shows the values of the reordered viscometer readings at different speeds starting from the low shear stresses 3 and $6 \mathrm{rpms}$ to moderate 100 and $200 \mathrm{rpms}$ and high shear stresses of 300 and $600 \mathrm{rpms}$. With increase the shear stress and the rotation speed per minute, the recorded value of shear rate is increasing. The same effect can be seen with increasing the

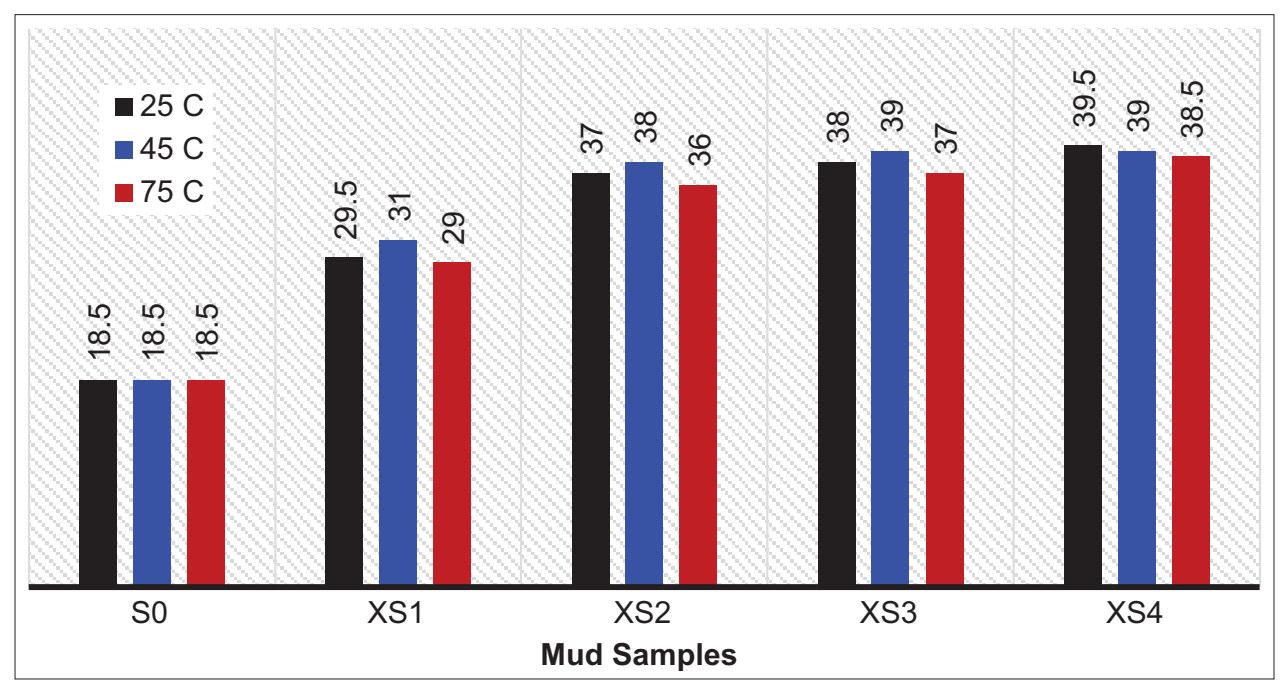

Fig. 6. Yield point measured at different concentrations of xanthan gum at 25,45 , and $75^{\circ} \mathrm{C}$.

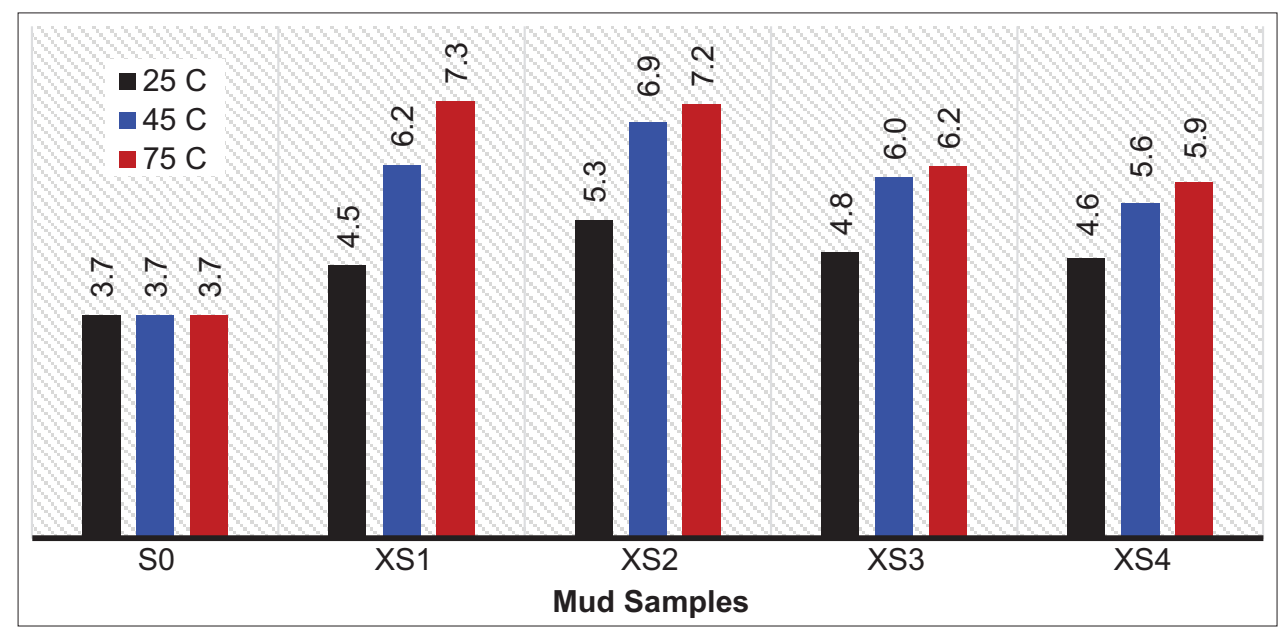

Fig. 7. Ratio of the yield point to plastic viscosity at different concentrations of xanthan gum at 25,45 , and $75^{\circ} \mathrm{C}$. 
concentration of the Katira gum. The measured results of the rheological properties including the apparent viscosity, PV, YP, and PV to YP ratio under the influence of the Katira gum are shown in Table 3 . The measurements are carried out under different temperature conditions of 25,45 , and $75^{\circ} \mathrm{C}$.

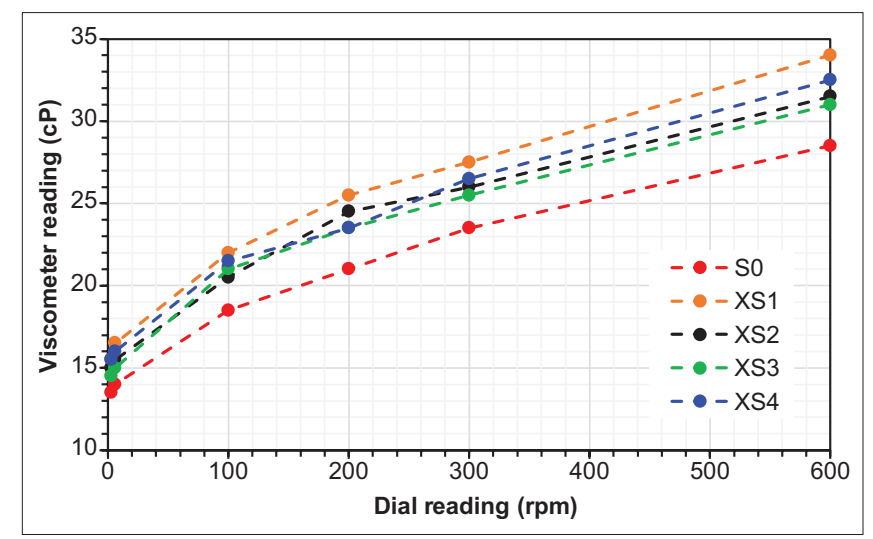

Fig. 8. Shear rate versus shear stress at different concentrations of natural Katira gum at $25^{\circ} \mathrm{C}$.
Fig. 9 illustrates the values of the apparent viscosity measured for the prepared drilling fluids containing the Katira gum at different concentrations of $20 \mathrm{mg}, 40 \mathrm{mg}, 60 \mathrm{mg}$, and $80 \mathrm{mg}$. As can be seen, the apparent viscosity of the base mud is increased from 14.25 to $17 \mathrm{cP}$ with adding $20 \mathrm{mg}$ of the Katira gum and continued to increase to $17.75 \mathrm{cP}$ with increasing the concentration of Katira to $40 \mathrm{mg}$. While, the apparent viscosity with all concentrations of xanthan gum is decreased with increasing the temperature of the experiment from 25 to 45 and $75^{\circ} \mathrm{C}$. In general, the impact of the Katira gum on the apparent viscosity under all concentrations and temperature conditions is low. Only small variation in the value of the apparent viscosity is noticed by changing the experiment conditions.

The PV behavior of the mud samples developed from different concentrations of Katira gum is shown in Fig. 10. As can be seen, the PV of the base fluid is increased by $23 \%$ from 5 to $6.5 \mathrm{cP}$ by adding $20 \mathrm{mg}$ Katira gum under $25^{\circ} \mathrm{C}$. However, the impact of the Katira in improving

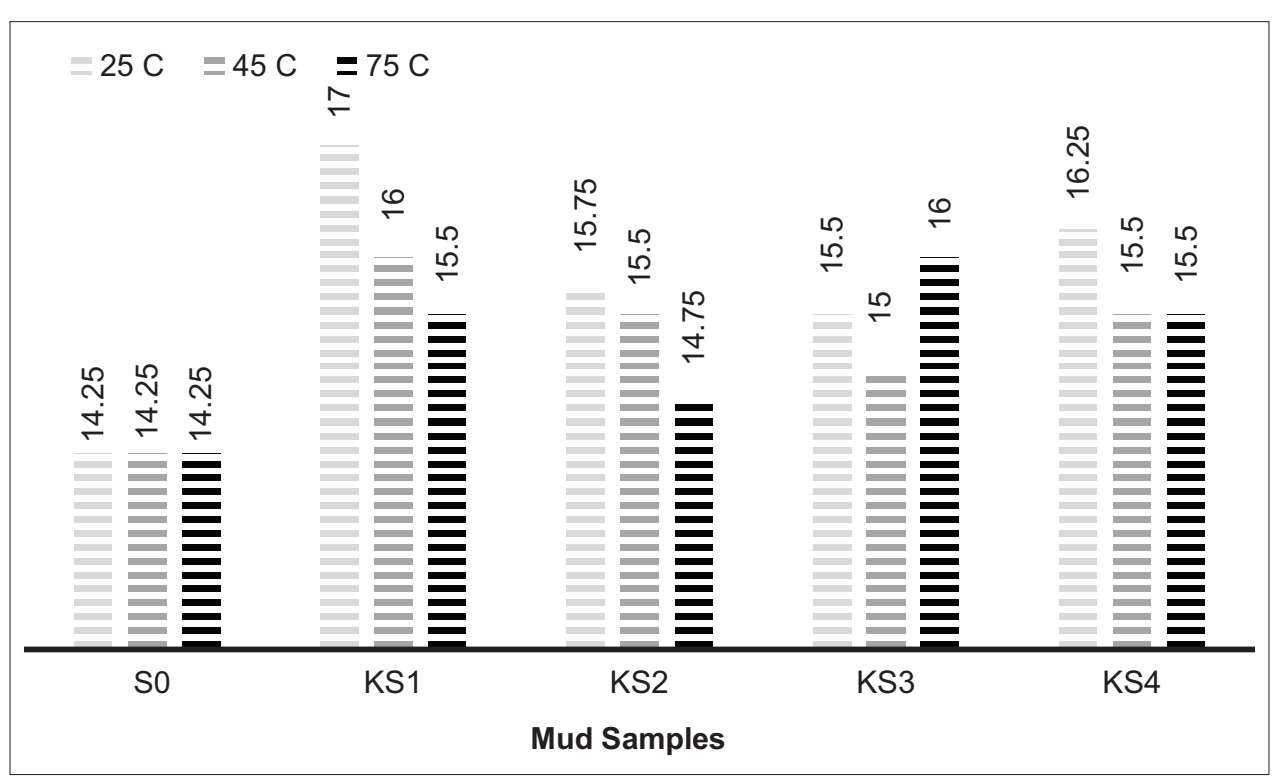

Fig. 9. Apparent viscosity measured at different concentrations of katira gum at 25,45 , and $75^{\circ} \mathrm{C}$.

TABLE 3: Measured rheological properties of drilling fluids under the influences of katira gum at 25, 45 , and $75^{\circ} \mathrm{C}$

\begin{tabular}{|c|c|c|c|c|c|c|c|c|c|c|c|c|}
\hline \multirow[t]{2}{*}{ Mud sample } & \multicolumn{3}{|c|}{$A V(c P)$} & \multicolumn{3}{|c|}{$P V(c P)$} & \multicolumn{3}{|c|}{ YP $\left(\mathrm{Ib} / 100 \mathrm{ft}^{2}\right)$} & \multicolumn{3}{|c|}{ YP/PV } \\
\hline & $25^{\circ} \mathrm{C}$ & $45^{\circ} \mathrm{C}$ & $75^{\circ} \mathrm{C}$ & $25^{\circ} \mathrm{C}$ & $45^{\circ} \mathrm{C}$ & $75^{\circ} \mathrm{C}$ & $25^{\circ} \mathrm{C}$ & $45^{\circ} \mathrm{C}$ & $75^{\circ} \mathrm{C}$ & $25^{\circ} \mathrm{C}$ & $45^{\circ} \mathrm{C}$ & $75^{\circ} \mathrm{C}$ \\
\hline So & 14.2 & 14.2 & 14.2 & 5.0 & 5.0 & 5.0 & 18.5 & 18.5 & 18.5 & 3.7 & 3.7 & 3.7 \\
\hline KS1 & 17.0 & 16.0 & 15.5 & 6.5 & 3.0 & 2.0 & 21.0 & 26.0 & 27.0 & 3.2 & 8.7 & 13.5 \\
\hline KS3 & 15.5 & 15.0 & 16.0 & 5.5 & 2.0 & 2.0 & 20.0 & 26.0 & 28.0 & 3.6 & 13.0 & 14.0 \\
\hline KS4 & 16.2 & 15.5 & 15.5 & 6.0 & 1.0 & 1.5 & 20.5 & 29.0 & 28.0 & 3.4 & 29.0 & 18.7 \\
\hline
\end{tabular}


the PV is lower when the temperature of the experiment and gum concentration are increased. This is true with Benyounes et al. [15], where they demonstrate that the rheological behavior of the polymer solution predominates compared to their clay suspension system. In this situation, the macroscopic behavior for the bentonite-Katira mixtures is influenced by the gum.

In addition, the values of the measured YPs for four prepared mud samples of Katira gum are shown in Fig. 11. The used
Katira gum left the highest impact on the YP compared with other properties of the drilling fluids which is about $36 \%$. The value of the YP is increased from 18.5 to 27 $\mathrm{lb} / 100 \mathrm{ft}^{2}$ with adding $20 \mathrm{mg}$ Katira, continued to increase to $29 \mathrm{lb} / 100 \mathrm{ft}^{2}$. Furthermore, the ratio of the YP to PV calculated from the measured properties of the drilling fluid samples under the influence of the Katira gum and different temperature is shown in Fig. 12. As is obvious, the ratio between two considered parameters is varied dependents on the concentration of the Katira gum and temperature.

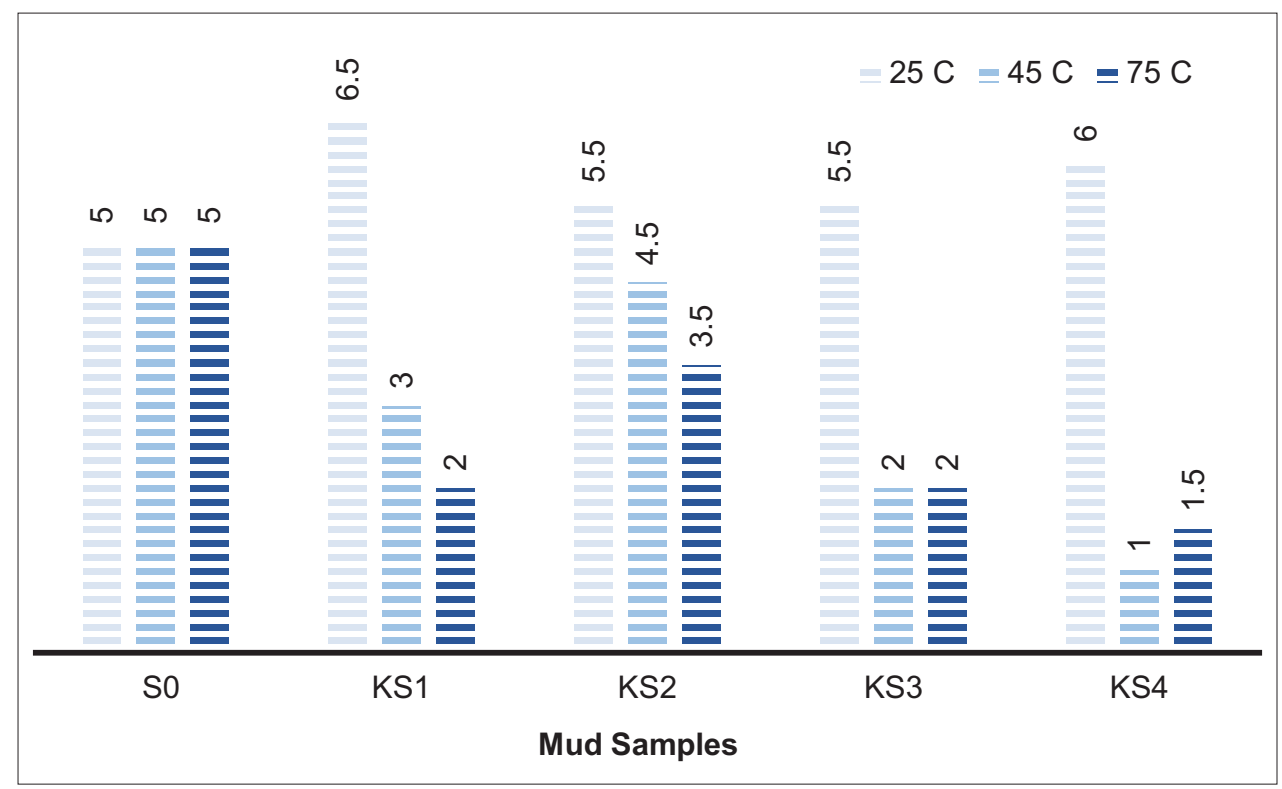

Fig. 10. Plastic viscosity measured at different concentrations of katira gum at 25,45 , and $75^{\circ} \mathrm{C}$.

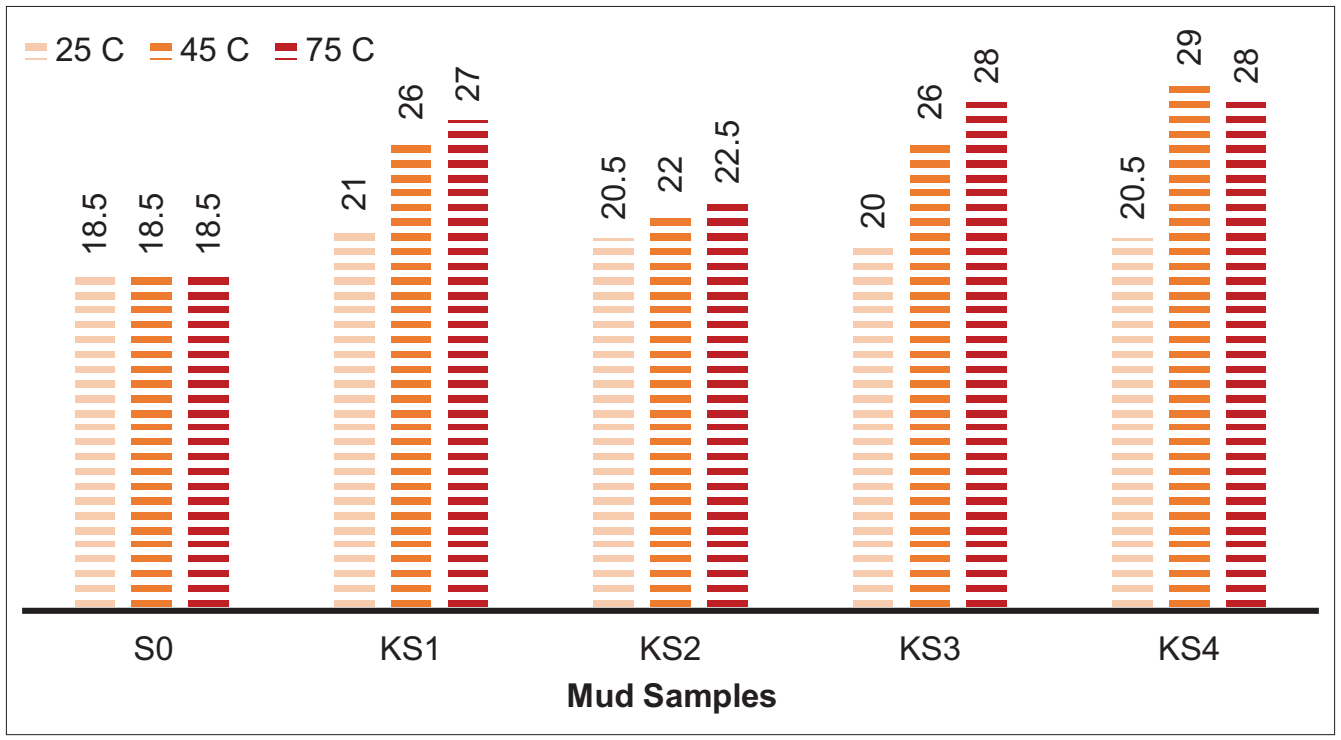

Fig. 11. Yield point measured at different concentrations of katira gum at 25,45 , and $75^{\circ} \mathrm{C}$. 


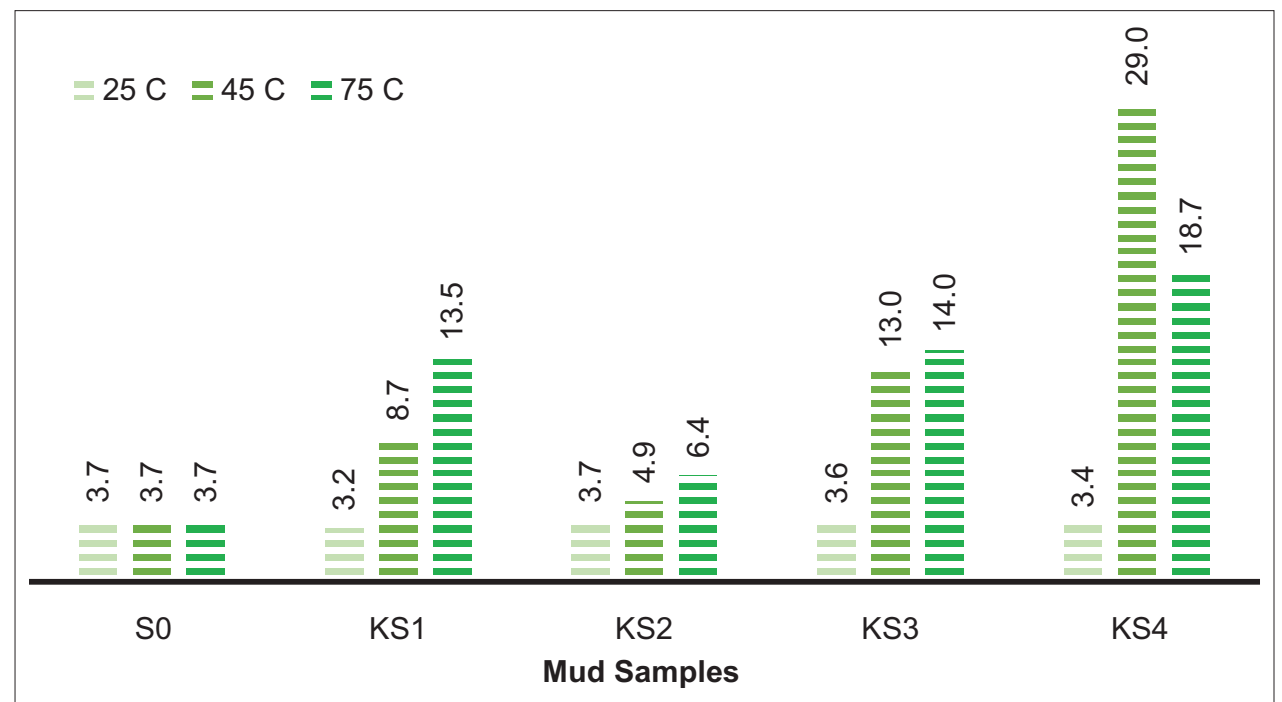

Fig. 12. Ratio of the yield point to plastic viscosity at different concentrations of katira gum at 25,45 , and $75^{\circ} \mathrm{C}$.

The high ratio between two parameters with KS4 samples are obtained, especially at high temperatures.

\section{CONCLUSION}

In this study, the rheological properties of the drilling mud under the influences of two polymer gums including xanthan and local Katira gums are investigated. In general, both types of gums are used at low concentrations and they left an important impact on the rheological behaviors of the drilling mud. However, xanthan gum presented a better performance in improving all studied rheological properties of the mud; apparent viscosity is increased from 14.25 to $28.35 \mathrm{cP}, \mathrm{PV}$ increased from 5 to $8.5 \mathrm{cP}$, and YP (18.5 to $\left.39.5 \mathrm{lb} / 100 \mathrm{ft}^{2}\right)$. While, the effect of the Katira gum is lower on apparent viscosity, PV, and YP under all different concentrations and temperatures.

\section{REFERENCES}

[1] K. L. Goyal. "A review of: Drilling and Drilling Fluids, by G. V. Chilingarian and P. Vorabutr; published in 1981 by Elsevier Scientific Publishing Co., P.O. Box 211, 1000 AE Amsterdam, The Netherlands; distributed by El-sevier/North-Holland, Inc., 52 Vanderbilt Avenue, New York, N. Y. 10017; 767 pp., photos, illustrations, appendices, glossary; $\$ 136.50$, U.S.: 1228.50, Rs". Energy Sources, vol. 7, no. 2, pp. 178-179, 1983.

[2] I. Imuentinyan and E. S. Adewole. "Feasibility study of the use of local clay as mud material in oil well drilling in Nigeria". In: Africa's Energy Corridor Oppor. Oil Gas Value Maximization Through Integration and Global Approach, Victoria Island, Lagos, vol. 2, pp. 1476-1491, 2014.

[3] A. W. A. Al-Ajeelt and S. N. Mahdi. "Sodium activation of Iraqi high grade montmorillonite clay stone by dry method". Iraqi Bulletin of Geology and Mining, vol. 9, no. 1, pp. 65-73, 2013.

[4] E. S. Al-Homadhi. "Improving local bentonite performance for drilling fluids applications". Journal of King Saud University Engineering Sciences, vol. 21, no. 1, pp. 45-52, 2007.

[5] K. A. Galindo, W. Zha, H. Zhou and J. P. Deville. "Clay-free high performance water-based drilling fluid for extreme high temperature wells". SPE/IADC Drilling Conference and Exhibition, 17-19 March, London, England, UK, pp. 179-188, 2015.

[6] S. D. Strickland. "Polymer Drilling Fluids". Journal of Petroleum Technology, vol. 46, no. 8, pp. 691-714, 1994.

[7] M. A. Tehrani, A. Popplestone, A. Guarneri and S. Carminati. "Water-based drilling fluid for HP/HT applications". International Symposium on Oilfield Chemistry, 28 February-2 March, Houston, Texas, USA, pp. 83-92, 2007.

[8] V. Mahto and V. P. Sharma. "Tragacanth gum: An effective oil well drilling fluid additive”. Energy Sources, vol. 27, no. 3, pp. 299-308, 2005.

[9] Y. Weikey, S. L. Sinha, and S. K. Dewangan. "Effect of different gums on rheological properties of slurry". IOP Conference Series Materials Science and Engineering, vol. 310, no. 1, p. 012068, 2018.

[10] C. Vipulanandan and A. S. Mohammed. "Hyperbolic rheological model with shear stress limit for acrylamide polymer modified bentonite drilling muds". Journal of Petroleum Science and Engineering., vol. 122, pp. 38-47, 2014.

[11] E. C. M. Vermolen, M. J. T. Van Haasterecht, S. K. Masalmeh, M. J. Faber, D. M. Boersma and M. Gruenenfelder. "Pushing the envelope for polymer flooding towards high-temperature and highsalinity reservoirs with polyacrylamide based ter-polymers". SPE Middle East Oil and Gas Show and Conference, 25-28 September, Manama, Bahrain., vol. 2, pp. 1001-1009, 2011.

[12] F. García-Ochoa, V. E. Santos, J. A. Casas and E. Gómez. "Xanthan gum: Production, recovery, and properties". Biotechnology Advances, vol. 18, no. 7, pp. 549-579, 2000.

[13] G. F. Sancet, M. Goldman, J. M. Buciak, O. Varela, N. D’Accorso, M. Fascio, V. Manzano, M. Luong. "Molecular 
Structure Characterization and Interaction of a Polymer Blend of Xanthan Gum-polyacrylamide to Improve Mobility-control on a Mature Polymer Flood. SPE EOR Conference at Oil and Gas West Asia, 26-28 March, Muscat, Oman, 2018.

[14] V. Mahto and V. P. Sharma. "Rheological study of a water based oil well drilling fluid". Journal of Petroleum Science and Engineering, vol. 45, no. 1-2, pp. 123-128, 2004.

[15] K. Benyounes, A. Mellak and A. Benchabane. "The effect of carboxymethylcellulose and xanthan on the rheology of bentonite suspensions". Energy Sources, Part A: Recovery, Utilization, and Environmental Effects, vol. 32, no. 17, pp. 1634-1643, 2010.

[16] A. Benmounah, K. Benyounes, K. Chalah and D. Eddine. "Effect of Xanthan Gum and Sodium Carboxymethylcellulose on the Rheological Properties and Zeta Potential of Bentonite Suspensions. 23 ${ }^{\text {rd }}$ Congrès Français de Mécanique, 2017.

[17] E. U. Akpan, G. C. Enyi and G. G. Nasr. "Enhancing the performance of xanthan gum in water-based mud systems using an environmentally friendly biopolymer". Journal of Petroleum Exploration and Production Technology, vol. 10, pp. 1933-1948, 2020.

[18] S. K. Dewangan and S. L. Sinha. "Effect of additives on the rheological properties of drilling fluid suspension formulated by bentonite with water". International Journal of Fluid Mechanics Research, vol. 44, no. 3, pp. 195-214, 2017.

[19] J. A. Ali, K. Kolo, S. M. Sajadi, K. H. Hamad, R. Salman, M. Wanli and S. M. Hama. "Modification of rheological and filtration characteristics of water-based mud for drilling oil and gas wells using green SiO2@ZnO@Xanthan nanocomposite". IET Nano Biotechnology, vol. 13, no.7, pp. 748-755, 2019.

[20] W. Xie and J. Lecourtier. "Xanthan behaviour in water-based drilling fluids". Polym. Degrad. Stab., vol. 38, no. 2, pp. 155-164, 1992.

[21] Z. Rončević et al., 'Effect of carbon sources on xanthan production by Xanthomonas spp. isolated from pepper leaves". Food and Feed Research, vol. 46, no. 1, pp. 11-21, 2019.

[22] P. F. D. Cano-Barrita and F. M. León-Martínez. "Biopolymers with viscosity-enhancing properties for concrete". In: Biopolymers and Biotech Admixtures for Eco-Efficient Construction Materials. Elsevier. Amsterdam, Netherlands, 2016.

[23] American Petroleum Institute. "13A Specification for Drilling Fluid Materials". $15^{\text {th }}$ ed. American Petroleum Institute, Washington, DC, United States, 1993. 